\title{
Triceps Anconeus Sparring Approach Versus Olecranon Osteotomy in Treatment of Intercondylar Fracture Humerus
}

\author{
MOHAMMED K. GODA, M.D.*; YASSER A. RADWAN, M.D.*; AYMAN M. MANSOUR, M.D.*; \\ YOUSEF M.A.H. AL-HEWAHY, M.Sc.**; AMR FAEK HAFEZ, M.Sc.*; EBEED YASIN, M.D.*; \\ REDA ALI SHETA, M.Sc.* and RAED A. ABDALLAH, M.Sc.* \\ The Department of Orthopaedic Surgery, Faculty of Medicine, Cairo University* and Al-Haram Hospital**
}

\begin{abstract}
Background: Intercondylar fracture humerus needs early treatment, anatomical reduction, rigid fixation and early ROM. This study hypothesized that Intercondylar fracture humerus better approached by olecranon osteotomy for comminuted types $\&$ by triceps anconeus sparring for simple two parts intercondylar fracture humerus.

Aim of Work: Is to compare classic olecranon osteotomy approach with triceps anconeus sparing approach (TRAP) in open reduction and internal fixation of intercondylar fracture humerus patients; regarding exposure of fracture site, operative time, post-operative pain, union time, return to pre fracture range of motion of elbow joint and complications rate. Comparing our results to the published series in the literatures.

Patients and Methods: A clinical study was conducted From January 2012 to October 2015. In this study, forty patients with intercondylar fracture humerus were treated by ORIF using triceps anconeus sparing and olecranon osteotomy approaches. Age ranges from 25 to 60 years. Elbow mayo score and muscle power used for scoring \& follow-up period 6 months.

Results: All patients were evaluated pre-operatively and post-operatively for Elbow mayo function score, wolf law for triceps power were completed at $1,3 \& 6$ months. Olecranon osteotomy gave better results in comminuted intercondylar fractures but triceps sparring was better in simple two part intercondylar humerus fractures especially in young patients.
\end{abstract}

Key Words: Triceps - Anconeus - Sparing-Olecranon.

\section{Introduction}

INTERCONDYLAR fracture humerus caused by fall down on outstretched hand, car accident or direct trauma. They make up to $3 \%$ of all adult fractures. Many of these fractures are stable two

Correspondence to: Dr. Mohammed K. Goda,

The Department of Orthopaedic Surgery, Faculty of Medicine, Cairo University parts articular fractures that can be treated satisfactorily with double plating and interfragmentary articular screws [1-3]. But 35-40\% are unstable three and four part fractures that are associated with high comminution and need many interfragmentary screws, k-wires with one or double plating fixation. In this study intercondylar fracture humerus opened by two approaches; Triceps anconeus sparing approach (TRAP) or classic olecranon osteotomy (chevron osteotomy) [4-6].

The olecranon osteotomy approach give good exposure but risk of delayed union of olecranon osteotomy and delayed mobilization of elbow give a chance for TRAP approach to preserves the olecranon and decreases operative time with early union and early mobilization of elbow [7-9] .

There is incidence of complications such as decreased range of motion, ulnar neuropathy, stiffness, infection, prominent metal and delayed union when these fractures are treated by internal fixation. The complications are related to malreduction of articular fragment, delayed union of fracture, bad handling of tissues during fixation and repair and delayed mobilization post-operative [11-13]

\section{Patients and Methods}

From January 2012 to October 2015, a prospective randomized study was undertaken at Kasr AlAiny Faculty of Medicine, Cairo University and Al-Haram Hospital. Forty patients with intercondylar fracture humerus were treated by ORIF using triceps anconeus sparing and olecranon osteotomy approaches. The age range from 25 to 60 years. Follow-up period 6 months. 
Inclusion criteria: Skeletally mature patient under age of 60 with Intercondylar fracture humerus.

Exclusion criteria: Vascular and neurological injuries, open fractures, old fracture presentation more than 2 weeks, uncooperative patients, pathological fracture, skeletally immature patients, previous elbow regional skeletal injury, markedly uncontrolled diabetes mellitus, immunocompromised patient, porotic bone.

Patients divided into two groups: Group A: Exposed by Olecranon Osteotomy approach \& Group B: Exposed by Triceps Anconeus Sparing approach (TRAP group).

\section{Sample size:}

Forty patients who met the inclusion criteria; divided by randomization into twenty patients underwent exposure by olecranon osteotomy approach (Group A) and twenty patients underwent exposure by triceps anconeus sparing approach (Group B). All patients included in the study were followed prospectively for 6 months.

- Plain X-ray: AP, lateral views of affected elbow and humerus. In case of car accident routine $\mathrm{X}$-rays are done. CT scan; determine fracture pattern and extension of fracture to articular surfaces $\&$ laboratory investigations.

Informed consent: All patients were consented about the surgery, possible risks, complication and follow-up protocol. They were also consented about randomization.

Operative technique: Olecranon osteotomy (chevron) \& Triceps anconeus sparing approach (TRAP).

Posterior trans-olecranon approach:It improves visualization of complex intra-articular distal humerus fractures. Place the patient in lateral decubitus position. Place the arm over an arm support. A radially curved posterior incision in midline of the limb extending from $10 \mathrm{~cm}$ proximal to olecranon and down to $7 \mathrm{~cm}$ distal to tip of the olecranon. Identify the ulnar nerve proximally at the medial border of the medial head of the triceps and dissect it free from its tunnel distally to its first motor branch [14-16].

Chevron intra-articular osteotomy with apex downwards is made $2-3 \mathrm{~cm}$ below the tip of the olecranon at the bare area, if visible, after reflection of capsular attachments from the sides of the olecranon; the bare area corresponds with the deeper part of the sigmoid notch, which is devoid of articular cartilage. The osteotomy was made with an oscillating saw, but not through the subchondral bone Fig. (1). The terminal part of the osteotomy completed by a thin osteotome, by fracturing through the osteochondral surface, which leaves an irregular osteochondral surface that can accurately interdigitate at time of fixation enhancing stability and union of fragments $[\mathbf{1 7 , 1 8 ]}$

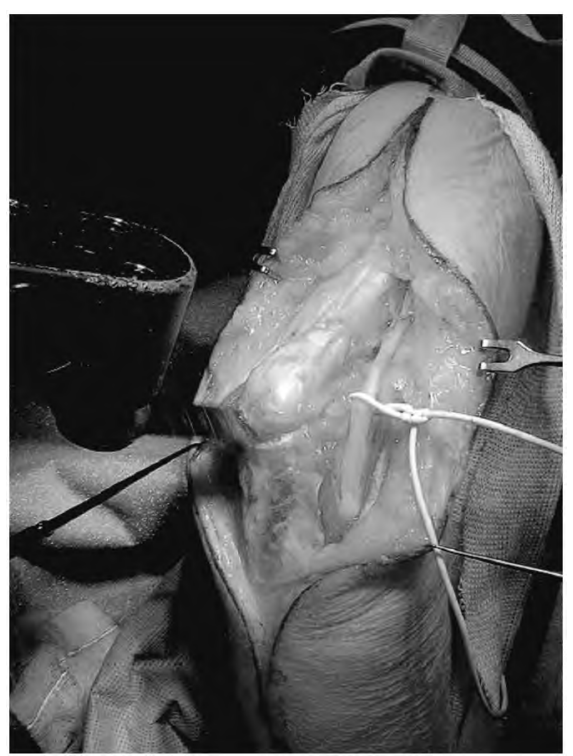

Fig. (1): Incomplete chevron osteotomy of olecranon by oscillating saw and then completed by sharp osteotomy [17]

The triceps muscle was elevated from medial and lateral inter-muscular septum; starting medially; the fracture exposed. After fixation of the fracture, Olecranon osteotomy was reduced and fixed with $2 \mathrm{~K}$. Wires and reinforced with dorsal ulnar tension band wiring $[12,19]$.

Post-operatively, ROM of elbow is started from 0-4 weeks post-operative. When pain tolerated, the wound was healed and sutures were removed.

\section{Triceps-anconeus sparing approach (TRAP):}

A superficial midline or curvilinear posterior incision is made just lateral to olecranon tip, the ulnar nerve is first localized proximally where it emerged beneath the triceps tendon. The distal aspect of the intermuscular septum is released to increase mobility of ulnar nerve. Take too much care to the nerve avoiding excessive traction or pressure by homans or retractors [20,21]. Laterally, the flap is elevated to expose the interval between the anconeus and extensor carpi ulnaris. The anconeus is first exposed distally; the exposure is developed proximally and the muscle is reflected upwards by developing the interval between exten- 
sor carpi ulnaris and the anconeus. The common extensor origin is left undisturbed on the humerus.

The anconeus-triceps flap was detached from its distal attachment (5-7cm from tip of olecranon) and dissected off lateral side of elbow and proximal ulna, preserving integrity of the lateral collateral ligament complex, including annular ligament.

This is accomplished easily by commencing the dissection distally and working proximally. The posterior capsule is incised and dissection is carried out proximally between the triceps and humerus by sharp and blunt dissection.

Now the entire triceps muscle with the posterior capsule is reflected upwards and laterally and elbow is flexed to expose the joint Fig. (2). Stay sutures are taken at this point. It is important to reattach the triceps precisely at that point after the completion of the procedure, so that the proper length-tension relationship is restored and the mechanical advantage of the olecranon is not lost. $[13,14]$.

Fixation by plates and interfragmentary screws now done and then Repair is done by transosseous

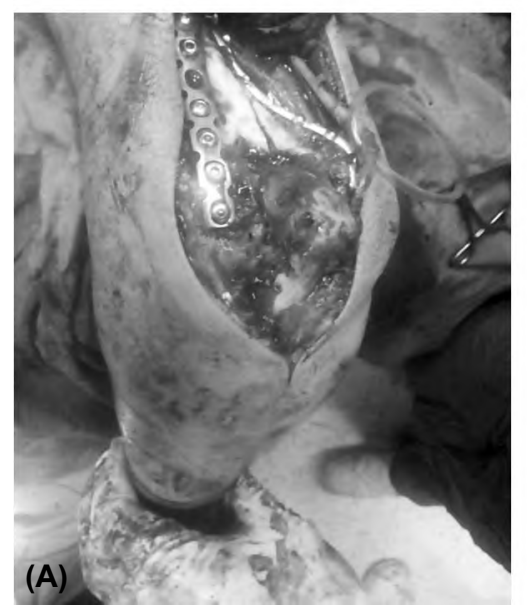

Fig. (3): Pinning for the olecranon and Transosseous sutures for triceps tendon repair.

Post-operative: Rehabilitation, radiological \& clinical evaluation of elbow function by Mayo score and Triceps power by wolfs law.

\section{Results}

Distribution of patients: Age from 2 1ys to 60ys. Sex; in olecranon osteotomy group there were twelve female and eight males. In TRAP group there were 7 female and thirteen males. In Group (A) osteotomy, Rt side affected 12 patients, Lt side affected 8 patients. In Group (B) TRAP, Rt side 9 patients, Lt side affected 11 patients. sutures through horizontal bone tunnels in the olecranon using non-absorbable suture (proline or ethibond). Patients undergoing repair with the above method usually have good functional recovery after a period of active strengthening exercise $[18,19]$

It's better to use the transosseous suture technique using 4 suture strand, instead of conventional 2 strands which provides better strength and more contact surface for tendon to bone healing. The period of immobilization is decreased and recovery period is fastened Fig. (3).

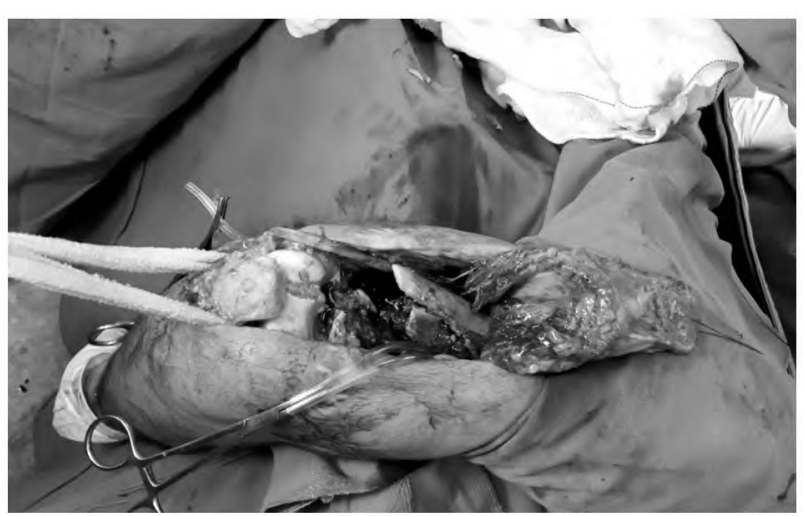

Fig. (2): Reflection of triceps and anconeus muscles.

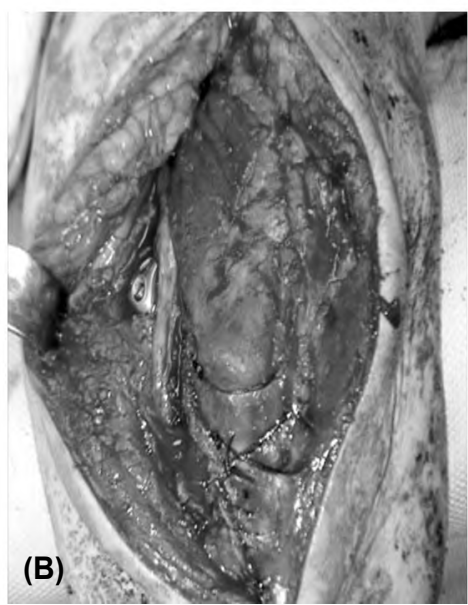

Radiological parameters: AP \& lateral of humerus and elbow were done. CT scan for elbow needed to detect fracture pattern \& extension \& intraoperative screening by image intensifier is mandatory.

Types of instrument and fixation used: In both groups same type of plates (recon.3.5), k wires, cancellous or cannulated screws can be used. Accurate planning of the type and levels of fixation for the fracture is performed mainly radiologically pre-operative. 
Associated fractures: Fracture ipsilateral distal radius 2 patients, ipsilateral both bones forearm 1 patients and metacarpal fractures 1 patient.

Associated diseases: Hypertension 6 patients and diabetes mellitus 3 patients.

Fracture pattern:High T shape, low T shape, Y shape and comminuted.

Time between the onset of the trauma and admission: The mean time interval between onset of trauma and admission in Group A was 1.5 day while in Group B was 2.5 days with no statistically significant difference among both groups.

Time between admission and surgery: Mean time interval between admission and operation in Group A was 5.5 days while in Group B was 6.5 days with no statistically significant difference among both groups.

Anesthesia \& operative technique: All patients anesthetized by general anesthesia. Prophylactic broad spectrum antibiotic ( 3 rd generation cephalosporin) was taken with induction of anesthesia and continued on for two days post operatively then switched to oral antibiotics for four days. Tourniquet was used. No complications occurred with anesthesia. Operative time and blood loss were recorded and blood transfusion if given.

Post-operative; post-operative elbow immobilization in a plaster splint is required from 2 days to 2 weeks to decrease pain. Documentation; operative time, blood loss and perioperative blood transfusion, intraoperative complications were documented in the patient notes.

Follow-up; patients in both groups were followed-up clinically by Mayo score, muscle power measured by Wolf law and radiological fracture union at 1, 3 and 6 months. Clinical and radiological parameters were checked each follow-up and documented in the patients notes.

Assessment of elbow function: Mayo Elbow performance score: Pain intensity, Arc of motion, stability \& Elbow applied clinical function. Muscle power assessed by system of Wolf et al.: Good, muscle acts against resistant, fair; muscle act against gravity, poor; muscle contraction but no joint movement $\&$ failure, no muscle contraction.

\section{Discussion}

The recommendations for treatment range widely from conservative treatment to open reduction and extensive internal fixation [8,9]. Conservative treatment has largely been abandoned because of its unsatisfactory results $[\mathbf{1 5 , 1 6 ]}$. The aim of operative treatment of these fractures is anatomic reduction and rigid fixation to allow early range of motion and finally to restore the pre-fracture elbow function [16,17].

Olecranon osteotomy has inherent complications that range from increasing surgical time, delayed union, non-union (10\%), malunion, prominent hardware $(25 \%)$, secondary procedures for removal of hardware (13\%) and the problem of non-union repair. So TRAP approach is used by some surgeon to avoid these complications.

Our results compared with the results of many clinical studies:

- Korner et al., found that extensor mechanism sparing approach to the elbow decrease operative time and avoid complications of olecranon osteotomy but give less visualization to fracture site $[13,14]$

- Mckee et al., operated 79 patients with intercondylar fracture humerus and find that olecranon osteotomy leads to less elbow stiffness and increased range of motion of the elbow than TRAP approach with less triceps weakness postoperative $[\mathbf{1 5 , 1 6 ]}$.

- O'driscoll et al., found that patients over 60ys treated via TRAP tended to have inferior function outcome in that they show more extension loss $[17,18]$.

- McCarty et al., reported on a series of 52 patients with delayed unions or non-unions of the distal humerus, ages 16 to 88 years, who underwent revision ORIF. A union rate of $98 \%$ was observed, with a $29 \%$ incidence of reoperation. The most commonly encountered indication for reoperation was painful hardware. Autologous bone grafting was used in 46 of 52 cases [18,20].

- Gupta et al., noted nonunion in two osteotomies out of 49 patients, and they advised chevron olecranon osteotomy and tension band wiring for fixation of osteotomies to overcome the problem [18,21]

- Soon \& Holds observed three delayed unions of olecranon osteotomies, but all three were transverse osteotomies as compared to chevron osteotomies $[1 \mathbf{1 9 , 2 0}]$.

Operative time: In our study, longer operative time was needed in osteotomy group because osteotomy and its fixation take longer time than triceps sparing in intercondylar fracture humerus. 
Blood loss and blood transfusion: In our study, In osteotomy group, more blood loss and more blood transfusion was needed than in TRAP group because osteotomy increase intraoperative blood loss which is difficult to be controlled.

All the studies mention above found that more blood was lost and more blood transfusion was needed in osteotomy group than TRAP group.

\section{Post-operative complications:}

Infection: Our rate was 10\% ( 2 cases). 5\% (1 case) was superficial infection and $5 \%$ (1 case) was deep infection in osteotomy group. While in TRAP group three patients $15 \%$, two patients were superficial managed by i.v. antibiotics according to culture while the third patient needs debridement 2 times with i.v. antibiotic coverage then improved and united. 3 patients from 5 who developed infection were diabetics which explain the high risk to develop infection than non-diabetic patients. Loosening: In our study, no loosening occurs in Group A during the follow-up period. But there was one patient with screws loosening \& delayed union in Group B. Implant failure: The reported failure rate $0.1 \%$. In our study no failure of implants reported during follow-up period.

\section{Conclusions:}

The purpose of treatment of intercondylar fractures of humerus is to prevent the probable complications by providing good fixation \& early mobilization and to help patients in returning to their prefracture elbow activities. Best radiographic analysis by A-P, lateral views of elbow joint. Intraoperative fluoroscopic C-arm is mandatory. C.T. is important for fracture pattern and planning.

The selection of the treatment in intercondylar fracture humerus depends on bone quality, general condition of the patient and level of elbow activity before fracture. The olecranon osteotomy approach provides adequate exposure, anatomic reduction of the joint, stable fixation to allow for early mobilization and good elbow function but more blood loss occur.

Reflecting triceps insertion and anconeus can be complete or incomplete according to need during exposure and fixation. Triceps tendon reflection can be done with small bone chip extraarticular to facilitate repair. Fixation can be done by closed $\mathrm{k}$. wires only in case of high risk patients \& Porotic bone. Reduction of articular fragments first then temporal fixation by $\mathrm{K}$. Wires and complete fixation by interfragmentary screws and plates or combina- tion of them. Early mobilization is very important for good ROM and outcome post-operative, early mobilization with osteotomy is better for union and elbow function as you did rigid fixation. Ulnar $\&$ radial nerves should be at great care during dissection. Articular surfaces and olecranon fossa must be checked for screws penetration.

\section{References}

1- YADAV V., SHARMA P. and GOHIYA A.: Functional outcome of intraarticular distal humerus fracture fixation using triceps-sparing paratricipital approach. Indian J. Orthop., 50: 595-601, 2016

2- BÉGUÉ T.: Articular fractures of the distal humerus. Orthop. Traumatol. Surg. Res., 100: S55-63, 2014.

3- ELMADAG M., ERDIL M., BILSEL K., ACAR M.A., TUNCER N. and TUNCAY I.: The olecranon osteotomy provides better outcome than the triceps-lifting approach for the treatment of distal humerus fractures. Eur. J. Orthop. Surg. Traumatol., 24: 43-50, 2014.

4- CHOU Y.C., HSU Y.H., YU Y.H. and WU C.C.: Tricepsreflecting the anconeus particle approach with double precontoured locking plate fixation is efficient in the treatment of orthopaedic trauma association type c distal humerus fracture. Injury, 47: 2240-6, 2016.

5- AZBOY I., BULUT M., ANCAR C., DEMIRTAŞ A., ÖZKUL E., GEM M., et al.: The comparison of tricepsreflecting anconeus pedicle and olecranon osteotomy approaches in the treatment of intercondylar fractures of the humerus. Ulus Travma Ve Acil Cerrahi Derg, 22: 5865, 2016.

6- SHAMSEER L., MOHER D., CLARKE M., GHERSI D., LIBERATI A., PETTICREW M., et al.: Preferred reporting items for systematic review and meta-analysis protocols (PRISMA-P) 2015: Elaboration and explanation. B.M.J., 349: g7647, 2015.

7- LJUNGQUIST K.L., BERAN M.C. and AWAN H.: Effects of surgical approach on functional outcomes of open reduction and internal fixation of intra-articular distal humeral fractures: A systematic review. J. Shoulder Elbow Surg., 21: 126-35, 2012.

8- XIE X., QIN H., SHEN L., ZENG B. and AN Z.: Open reduction and bi-columnar internal fixation of intraarticular distal humerus fractures through a combined medial and lateral approach. Eur. J. Orthop. Surg. Traumatol., 24: 1115-22, 2014

9- MIGHELL M.A., STEPHENS B., STONE G.P. and COTTRELL B.J.: Distal humerus fractures: Open reduction internal fixation. Hand. Clin., 31: 591-604, 2015.

10-NAUTH A., McKEE M.D., RISTEVSKI B., HALL J. and SCHEMITSCH E.H.: Distal humeral fractures in adults. J. Bone Jt. Surg., (A), 93: 686-700, 2011.

11-ATHWAL G.S., HOXIE S.C., RISPOLI D.M. and STEINMANN S.P.: Precontoured parallel plate fixation of AO/OTA type $\mathrm{C}$ distal humerus fractures. J. Orthop. Trauma., 23: 575-80, 2009. 
12- BERGDAHL C., EKHOLM C., WENNERGREN D., NILSSON F. and MÖLLER M.: Epidemiology and pathoanatomical pattern of 2,011 humeral fractures: Data from the Swedish fracture register. B.M.C. Musculoskelet. Disord., 17: 159, 2016.

13- SANCHEZ-SOTELO J., TORCHIA M.E. and O'DRISCOLL S.W.: Complex distal humeral fractures: Internal fixation with a principle- based parallel-plate technique. J. Bone Jt. Surg., 89: 961-9, 2011.

14- KORNER J., LILL H., MULLER L.P., HESSMANN M., et al.: Distal humerus fractures in elderly patients: Results after open reduction and internal fixation. Osteoporos. Int., 16, Suppl. 2: S73-79, 2016.

15- MCKEE M.D., WINSTON L., et al.: Functional outcome following surgical treatment of intra-articular distal humeral fractures through a posterior approach. J. Bone Joint Surg. Am., 82-A: 1701-7, 2016.

16- O'DRISCOLL S.W.: Optimizing stability in distal humeral fracture fixation. J. Shoulder. Elbow Surg., 14: 186S194S, 2015.

17- O'DRISCOLL S.W.: The triceps-reflecting anconeus pedicle (TRAP) approach for distal humeral fractures and nonunions. Orthop. Clin. N. Amer., 31: 91-101, 2013.

18- KORNER J., DIEDERICHS G., ARZDORF M., LILL H., JOSTEN C., SCHNEIDER E. and LINKE B.: A biome- chanical evaluation of methods of distal humerus fracture fixation using locking compression plates versus conventional reconstruction plates. J. Orthop. Trauma., 18: 28693, 2014.

19- SELF J., VIEGAS S.F., BUFORD W.L. Jr. and PATTERSON R.M.: A comparison of double-plate fixation methods for complex distal humerus fractures. J., Shoulder Elbow Surg., 4: 10-6, 2016.

20- SOON J.L., CHAN B.K. and LOW C.O.: Surgical fixation of intraarticular Fractures of the distal humerus in adults. Injury, 35: 44-54, 2014.

21- TYLLIANAKIS M., PANAGOPOULOS A., PAPADOPOULOS A.X., KAISIDIS A. and ZOUBOULIS P. Functional evaluation of comminuted intra-articular fractures of the distal humerus (AO type $\mathrm{C}$ ). Long term results in twenty-six patients. Acta Orthop. Belg., 70: 123-30, 2016.

22- HUANG T.L., CHIU F.Y., CHUANG T.Y. and CHEN T.H.: The results of open reduction and internal fixation in elderly patients with severe fractures of the distal humerus: A critical analysis of the results. J. Trauma, 58: 62-9, 2015.

23- GUPTA R. and KHANCHANDANI P.: Intercondylar fractures of the distal humerus in adults: A critical analysis of 55 cases. Injury, 33: 511-5, 2012.

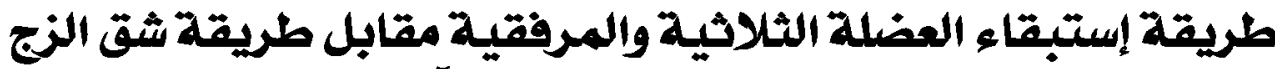 فى علاج كسور ما بين اللقمتين لآسفل العضد العضد}

$$
\begin{aligned}
& \text { يعتبر مفصل المرفق مفصلا جوهريا لوظيفة الطرف العلوى واليد لآنه يغير وضع اليد في الفضاء فهو يسمح الليد بالوصول إلى البه البدن، الرآس، }
\end{aligned}
$$

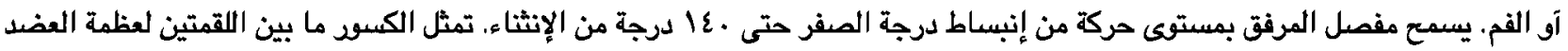

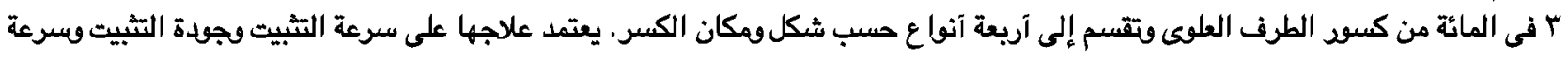

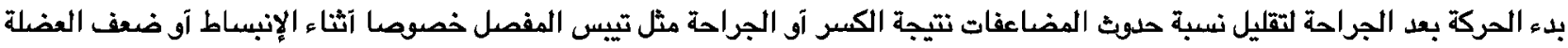

$$
\begin{aligned}
& \text { الثلاثية آو تآخر إلتئام الكسر . } \\
& \text { توجد طرق مختلفة للحصول على بؤية جيدة لثبيت كسور ما بين لقمتى العضد آهمها شاق الزج آو طريقة إستبقاء العضلة الثقاثية والمرفقية }
\end{aligned}
$$

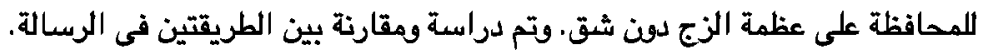

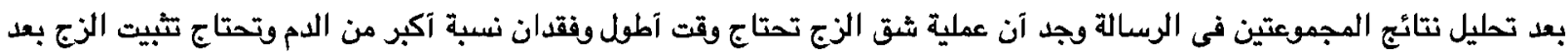

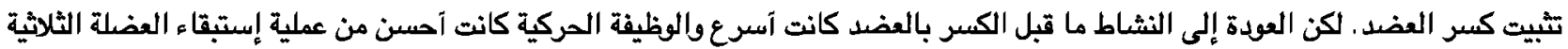

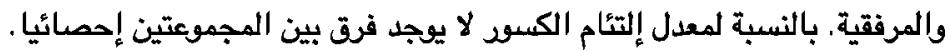

